\title{
CAPACIDADE COMBINATÓRIA DE LINHAGENS E SELEÇÃO DE HÍBRIDOS DE SORGO GRANÍFERO
}

\author{
CÍCERO BESERRA DE MENEZES ${ }^{1}$, CRISLENE VIEIRA DOS SANTOS², \\ DOUGLAS CIRINO SALDANHA ${ }^{3}$, MARCOS PAULO MINGOTE JÚLIO², KARLA JORGE DA SILVA ${ }^{4}$, \\ CELSO HENRIQUE TUMA E SILVA² e JOSÉ AVELINO SANTOS RODRIGUES ${ }^{1}$
}

\author{
${ }^{1}$ Embrapa Milho e Sorgo, Sete Lagoas, MG,Brasil, cicero.menezes@embrapa.bre avelino.rodrigues@embrapa.br \\ ${ }^{2}$ UFSJ, Sete Lagoas, MG,Brasil,cris-vieira15@hotmail.com,marcospmj@yahoo.com.br, celsotuma@yahoo.com.br \\ ${ }^{3}$ Unifemm, Sete Lagoas, MG, Brasil, douglasaldanha77@hotmail.com \\ ${ }^{4} U F V$, Viçosa, MG, Brasil, Karla.js@hotmail.com
}

Revista Brasileira de Milho e Sorgo, v.16, n.3, p. 509-523, 2017

\begin{abstract}
RESUMO - O objetivo do presente trabalho foi selecionar parentais e híbridos de sorgo granífero para características agronômicas. Foram avaliados 184 cruzamentos oriundos de um dialelo parcial envolvendo 16 linhagens machoestéreis e 12 restauradoras da fertilidade. Foram realizados 8 experimentos, com 23 híbridos cada e duas testemunhas adicionais (BRS 304 e BRS 330), em blocos casualizados, com duas repetições. Foram avaliadas as características rendimento de grãos, florescimento e altura de plantas. Os efeitos de CGC e CEC foram significativos para as três características, mostrando a importância dos efeitos aditivos e dominantes no controle destes caracteres. O quadrado médio para CGC foi superior ao da CEC. Todos os parentais que contribuíram para aumentar o rendimento de grãos também o fizeram para altura de plantas, exceto pelos parentais femininos CMSXS 1006 e CMSXS 1011, mostrando a dificuldade de dissociar estas duas características. Os híbridos mais produtivos apresentaram altura de plantas acima do recomendado para sorgo granífero, mesmo assim foi possível a seleção de cruzamentos que apresentaram rendimento de grãos acima da média, florescimento abaixo da média e altura dentro do padrão exigido. Dentre estes, pode-se destacar os híbridos CMSXS 1002 x CMSXS 1102, CMSXS 1006 x RTx2907, ATx ARG 1 x SC1155 e CMSXS 1008 $\mathrm{x}$ Tx2741.
\end{abstract}

Palavras-chave: Sorghum bicolor, seleção de parentais, dialelo, hibridação, melhoramento de plantas.

\section{COMBINING ABILITY OF LINES AND SELECTION OF GRAIN SORGHUM HYBRIDS}

\begin{abstract}
The purpose of this work was to select grain sorghum lines and hybrids for growing as succession crop. Crosses, coming from a partial diallel involving 16 male sterile lines and 12 restorer lines, were evaluated. Eight experiments were carried out with 23 hybrids each and two additional checks (BRS 304 and BRS 330) in randomize complete blocks design, with two replications and plot of two lines of five meters long. Grain yield, days to flowering and plant height were evaluated. The effects of GCA and SCA were significant, showing the importance of both additive and dominant effects in the control of these traits. The mean square for GCA was well above the SCA, suggesting the importance of parental selection in sorghum. Only the lines CMSXS 1006 and CMSXS 1011 contributed to rise grain yield without increasing the plant height in the hybrids they compose. The most productive hybrids showed plants above $150 \mathrm{~cm}$, however it was still possible to get crossings that had yield above average, cycle below average and plant height within the standard required for grain sorghum. Among these are the hybrids CMSXS 1002 x CMSXS 1102, CMSXS 1006 x RTx2907, ATX ARG 1 x SC1155 and CMSXS 1008 x Tx2741, with high yields and CEC.
\end{abstract}

Keywords: Sorghum bicolor, parental selection, diallel, hybridization, crop breeding. 
O sorgo (Sorghum bicolor) está entre os cereais mais importantes do mundo, sendo responsável pela alimentação de milhões de pessoas em países na África e Ásia. No Brasil, o sorgo é utilizado para alimentação animal, respondendo por parte importante da oferta de grãos para suprir demanda da indústria de rações. Dados atuais do USDA indicam uma produção mundial de 62,6 milhões de toneladas, em 42 milhões de hectares e produtividade de 1,5 $\mathrm{t} \mathrm{ha}^{-1}$ (USDA, 2017). O Brasil produziu 1,9 milhão de toneladas, na última safra 2016/17, numa área de $634 \mathrm{mil}$ hectares e rendimento de 2,9 $\mathrm{t} \mathrm{ha}^{-1}$ (CONAB, 2017). O sorgo possui potencial produtivo acima de $7 \mathrm{t} \mathrm{ha}^{-1}$, necessitando de pesquisas e extensão para que essa produtividade seja atingida pelo produtor.

No Brasil, o sorgo é plantado principalmente em sucessão à soja. Na região Sul, o sorgo é plantado no verão, no Sudeste e Centro-Oeste seu plantio se dá nos meses de fevereiro e março, e no Nordeste, no início das chuvas, geralmente em março/abril. O Sudeste e Centro-Oeste respondem por mais de $85 \%$ da produção nacional de sorgo. $\mathrm{O}$ mercado de sementes de sorgo exige que a cultivar seja altamente produtiva, de ciclo precoce e altura de plantas entre $100 \mathrm{e}$ $150 \mathrm{~cm}$. Outras características importantes para cultivo de safrinha são tolerância a doenças, principalmente antracnose, e tolerância à seca (Santos et al., 2005; Menezes et al., 2015).

O melhoramento de plantas tem contribuído com importantes materiais genéticos no intuito de aumentar a produtividade da cultura do sorgo. Novos híbridos são lançados anualmente pelas empresas de sementes com novos atributos para superar estresses bióticos e abióticos. Na obtenção de híbridos, pelos programas de melhoramento, pelo menos quatro etapas estão envolvidas: a escolha das populações segregantes, a obtenção das linhagens, a avaliação da capa- cidade de combinação das linhagens e o teste extensivo das combinações híbridas obtidas (Paterniani \& Campos, 2005; Ramalho et al., 2012). Destas etapas, uma das mais importantes é a seleção das linhagens a serem cruzadas.

A escolha dos genótipos mais promissores para serem utilizados como progenitores em cruzamentos permite que a maioria dos esforços seja dedicada àquelas populações segregantes potencialmente capazes de fornecer progênies superiores, traduzindo-se em maior eficiência do programa de melhoramento. A técnica de cruzamentos dialélicos assume grande importância nesta questão, pois auxilia o melhorista na escolha de progenitores com base nos seus valores genéticos e, principalmente, considerando a sua capacidade de se combinarem em híbridos promissores (Cruz et al., 2012).

Os conceitos de capacidade geral de combinação (CGC) e capacidade específica de combinação (CEC) são muito importantes para caracterizar qualidades genéticas dos genótipos, sendo a CGC representada pelos efeitos genéticos aditivos, com elevada importância na determinação de genótipos promissores para o melhoramento dentro de uma população, e a CEC sendo representada pelo desvio do que se espera em relação a CGC, ou seja, interações de dominância e epistasia. $\mathrm{O}$ estudo da capacidade combinatória pode ser feito a partir do uso de dialelos de meia tabela, em que se tem acasalamentos entre $p$ genitores, e o número de combinações será $\mathrm{p}(\mathrm{p}-1) / 2$, faltando os progenitores e os cruzamentos recíprocos.

O objetivo do presente trabalho foi avaliar o desempenho de híbridos experimentais e estimar parâmetros genéticos de linhagens-elites de sorgo granífero, para as características rendimento de grãos, dias para florescimento e altura de plantas, buscando selecionar híbridos de alto rendimento, precoces e com 
altura para padrão granífero, assim como parentais que contribuam para aumentar o rendimento de grãos, reduzam o ciclo e não aumentem a altura de plantas de seus híbridos.

\section{Material e Métodos}

Os experimentos foram conduzidos no ano agrícola de 2014, na estação experimental da Embrapa Milho e Sorgo, localizada em Sete Lagoas-MG, tendo sido avaliados 184 híbridos experimentais de sorgo granífero, oriundos do cruzamento de 16 linhagens macho-estéreis com 12 linhagens restauradoras da fertilidade. Por se tratar de número elevado de híbridos e pouca disponibilidade de sementes para número adequado de repetições, optou-se pelo delineamento de blocos casualizados com testemunhas adicionais, e duas repetições por experimento. Os 184 híbridos foram divididos em oito experimentos com vinte e três tratamentos, mais duas testemunhas adicionais (BRS 304 e BRS 330), perfazendo um total de vinte e cinco tratamentos por experimento.

As parcelas foram compostas por duas linhas de $5 \mathrm{~m}$ com espaçamento de $0,5 \mathrm{~m}$ entre linhas, conservando-se 10 plantas por metro de sulco após desbaste. Ambos, plantio e colheita, foram mecanizados.

A adubação de plantio consistiu da aplicação de $300 \mathrm{Kg} \mathrm{ha}^{-1}$ da formulação 8-28-16 (N-P-K) e para a adubação de cobertura foi utilizada a dose de 150 $\mathrm{Kg} \mathrm{ha}^{-1}$ de ureia, 30 dias após o plantio. O plantio foi realizado em 20 de fevereiro de 2014 , e a colheita realizada em 26 de junho de 2014. O manejo das plantas daninhas foi realizado quimicamente por meio da aplicação dirigida do herbicida atrazina na dosagem de $3 \mathrm{~L} \mathrm{ha}^{-1}$. Mais uma capina manual foi realizada para manter o campo experimental limpo. Os demais tratos culturais foram realizados de acordo com as re- comendações para a cultura do sorgo para a região.

As características avaliadas foram: florescimento de plantas, mensurado pela contagem de dias decorridos da semeadura até o florescimento de 50\% das plantas pertencentes à área útil da parcela; altura de plantas, mensurada em $\mathrm{cm}$, medida do colo da planta até a ponta da panícula, realizada em dois pontos da parcela útil; e rendimento de grãos. Para a avaliação do rendimento, foram colhidas todas as plantas da área útil, as quais foram trilhadas, tiveram corrigida a umidade dos grãos para $13 \%$, e posteriormente extrapolada para toneladas por hectare.

Para cada característica, foram realizados análise de variância e teste $\mathrm{F}$, com o auxílio do programa GENES (Cruz, 2013), utilizando o modelo de análise agrupada de blocos. Neste procedimento são realizadas análises de grupos de experimentos com tratamentos comuns e não comuns. Por meio do procedimento, são estimados componentes de variância e covariância (fenotípica, genotípica e ambiental), a herdabilidade, os coeficientes de variação (genético e experimental) e as correlações (fenotípicas, genotípicas e de ambiente) entre todos os pares de caracteres estudados.

A opção análise de grupos de experimentos do GENES fornece todas as matrizes de covariâncias e correlações de natureza fenotípica, genotípica ou de ambiente. Além destas matrizes, que podem ser gravadas, o programa fornece as médias ajustadas dos tratamentos avaliados.

Com as médias ajustadas, foi realizada a análise dialélica de acordo com o Método IV de Griffing (1956), que estima os efeitos da capacidade geral de combinação (CGC) de cada parental e os efeitos da capacidade específica de combinação (CEC), para dialelos parciais utilizando somente os híbridos $\mathrm{F}_{1} \mathrm{O}$ programa GENES permite as estimativas dos valores 
dos cruzamentos perdidos. No presente trabalho, foram estimados oito cruzamentos perdidos, totalizando na análise dialélica 192 cruzamentos.

\section{Resultados e Discussão}

A análise de variância conjunta (dados não apresentados) mostrou que a interação testemunhas (tratamentos comuns) e experimentos foi não significativa, indicando reduzido efeito ambiental no desempenho das testemunhas, podendo as estimativas de médias ajustadas e comparações entre os experimentos serem interpretadas com maior precisão. Os coeficientes de variações (CV\%) foram médios para rendimento de grãos $(19,57 \%)$ e baixos para florescimento (3,33\%) e altura de plantas (7,98\%) (Tabela 1$)$. A característica rendimento de grãos é sabida ser mais influenciada pelo ambiente do que as outras duas características, principalmente pelo caráter poligênico, e ser muito dependente dos vários processos fisiológicos da planta.

Estimativas de parâmetros genéticos como variância, herdabilidade e razão entre Coeficiente de Variação Genético e Ambiental (CVg/CVe) de uma população permitem fazer inferências sobre a variabilidade genética que esta apresenta, possibilitando estimativas de ganho genético e escolha de métodos de seleção. A herdabilidade no sentido amplo $\left(h^{2}\right)$ foi média para florescimento $(63,21 \%)$, e alta para rendimento de grãos $(89,67 \%)$ e altura de plantas $(94,87 \%)$ (Tabela 1). A herdabilidade define a proporção genética de cada caráter que será transmitido à geração seguinte, e reflete a variabilidade genética do caráter, sendo quanto maior melhor.

A alta variabilidade genética destas famílias pode também ser observada pela estimativa da relação entre o coeficiente de variação genético e ambiental
(CVg/CVe), o qual mostra a proporção da variância genética em relação ao erro residual, eliminando a influência da média populacional. As estimativas $\mathrm{CVg}$ / CVe foram acima de 1 (Tabela 1) para rendimento de grãos e altura de plantas, indicando condição favorável para seleção destas características nos cruzamentos estudados.

A partir das análises dos híbridos foi possível realizar estimativas de capacidade geral de combinação para as linhagens envolvidas nos cruzamentos. Esta técnica auxilia na escolha de progenitores com base nos seus valores genéticos, considerando a sua capacidade de se combinarem em híbridos promissores (Ramalho et al., 2012; Cruz et al., 2012). A escolha das melhores linhagens para progenitores em programas de cruzamento permite que a maioria dos esforços seja dedicada àquelas populações segregantes, potencialmente capazes de fornecer progênies superiores, traduzindo-se em maior eficiência do programa de melhoramento.

As estimativas de Capacidade Geral de Combinação para as linhagens macho-estéreis (CGC I) e para as linhagens restauradoras da fertilidade (CGC II), assim como a Capacidade Específica de Combinação (CEC), foram significativas para as três características avaliadas, o que revela a importância de ambos os efeitos aditivos e de dominância no controle destes caracteres (Tabela 1).

A avaliação da natureza e magnitude dos efeitos gênicos que controlam os vários caracteres quantitativos é um dos principais objetivos em um programa de melhoramento de plantas. Para tanto, é fundamental investigar, na fração genética, as proporções que podem ser atribuídas a fatores gênicos aditivos, dominantes e epistáticos. Essa avaliação está intimamente relacionada com os objetivos do programa de melhoramento, e esses tipos de ação gênica podem 
Tabela 1. Análise de variância para capacidade de combinação geral (CGC) e específica (CEC), com a decomposição da soma de quadrados de genótipos (Cruzamentos), e estimativa de parâmetros genéticos, para 192 híbridos resultantes dos cruzamentos de 16 linhagens macho-estéreis (CGC I) e 12 linhagens restauradoras (CGC II) de sorgo granífero. Sete Lagoas-MG. 2014.

\begin{tabular}{|c|c|c|c|c|}
\hline \multirow[t]{2}{*}{$\mathrm{FV}^{1}$} & \multirow[t]{2}{*}{ GL } & Rendimento de Grãos $\left(\mathrm{t} \mathrm{ha}^{-1}\right)$ & $\begin{array}{l}\text { Florescimento } \\
\text { (Dias) }\end{array}$ & Altura de plantas $(\mathrm{cm})$ \\
\hline & & \multicolumn{3}{|c|}{ Quadrados Médios } \\
\hline Cruzamentos & 191 & 9,4591 & 18,2898 & 3181,23 \\
\hline CGC I & 15 & $11,7787 * *$ & $58,9654 * *$ & $3984,84 * *$ \\
\hline CGC II & 11 & $89,4787 * *$ & $100,1818^{* *}$ & $44288,77 * *$ \\
\hline $\mathrm{CEC}$ & 165 & $3,9136^{* *}$ & $9,1325^{* *}$ & $367,68 * *$ \\
\hline RESÍDUO & 192 & 1,0011 & 5,4775 & 180,77 \\
\hline $\mathrm{CV} \%$ & & 19,57 & 3,33 & 7,98 \\
\hline MÉDIA & & 5,08 & 67,30 & 164,66 \\
\hline $\mathrm{DP}(\mathrm{u})$ & & 0,0511 & 0,1194 & 0,6861 \\
\hline$h^{2}(\%)$ & & 89,67 & 63,21 & 94,87 \\
\hline $\mathrm{CVg} / \mathrm{CVe}$ & & 2,02 & 0,93 & 2,99 \\
\hline
\end{tabular}

** Significativo a $1 \%$ de probabilidade pelo teste $\mathrm{F}$.

${ }^{1}$ CGC I: Capacidade Geral de Combinação das linhagens macho-estéreis; CGC II Capacidade Geral de Combinação das linhagens restauradoras; CEC: Capacidade Específica de Combinação; CV\%: Coeficiente de Variação; DP(u): desvio padrão médio; h²: Herdabilidade no sentido amplo; CVg/CVe: Razão entre o Coeficiente de Variação Genético e o Coeficiente de Variação Ambiental.

ser usados para explicar a expressão heterótica, assim como a depressão endogâmica. A superioridade dos valores dos quadrados médios da CGC sobre os CEC é indicativo da maior importância da variabilidade gênica aditiva sobre a não aditiva. No presente trabalho, os efeitos de CGC foram bem superiores aos efeitos de CEC, e o quadrado médio da CGC dos machos (grupo II) foi também superior ao das fêmeas (grupo I), mostrando maior variância das linhagens restauradoras.

Outros trabalhos em sorgo também apresentaram a importância da CGC em relação a CEC para características de rendimento de grãos e florescimento de plantas (Menezes et al., 2014; Kenga et al., 2004). A maior variabilidade das linhagens restauradoras, em relação às linhagens macho-estéreis, é esperada, uma vez que nos programas de melhoramento de sorgo o número de linhagens macho-estéreis é menor do que de linhagens restauradoras, por causa principalmente do tempo de obtenção e esterilização da linhagem mantenedora (Rooney, 2012; Silva, 2016). A produção de híbridos de sorgo é realizada a partir do cruzamento de uma linhagem A (macho-estéril) com uma linhagem $\mathrm{R}$ (restauradora de fertilidade). Para multiplicação da linhagem macho-estéril é necessária uma outra linhagem chamada B (mantenedora da fertilidade). Portanto, no programa de melhoramento de sorgo após a obtenção da linhagem B, ela precisa ser retrocruzada com uma linhagem A durante seis gerações, o que basicamente dobra o tempo de obtenção da linhagem macho-estéril.

As estimativas dos efeitos da capacidade geral de combinação das 16 linhagens macho-estéreis (CGC I), para as características rendimento de grãos, florescimento e altura de plantas, encontram-se na Figura 1. Elevados valores positivos para as estimativas 
de CGC indicam que a média dos cruzamentos que envolvem um determinado genitor é superior à média geral de todos os genitores envolvidos. Por conseguinte, reduzidos valores (e positivos) são indicativos de que o valor da capacidade geral de combinação dos genitores não difere expressivamente da média geral dos cruzamentos dialélicos (Cruz et al., 2012). A recomendação dos genitores mais promissores para inclusão em programas de seleção é realizada com base nestas estimativas, pois possibilita a comparação da importância relativa dos efeitos da capacidade geral de combinação (CGC) dos vários genitores envolvidos (Ramalho et al., 2012).

Entre as 16 linhagens de sorgo macho-estéreis (Grupo I), os maiores valores de CGC relativos a rendimento de grãos foram obtidos para CMSXS 230A $(1,10)$, CMSXS 1002 (0,80), A8905 (0,79), CMSXS 1006 $(0,72)$ e CMSXS $1008(0,66)$, enquanto B3 8902 A $(-1,01)$, CMSXS 156A $(-0,89)$, Tx643A $(-0,88)$, e A8911 (-0,62) apresentaram os menores valores (Figura 1). Para florescimento os parentais SC $720(-1,6)$, SC 1211(-2,5), RTx2907 (-2,4) e Tx2741 (-1,1) foram os melhores por reduzirem o ciclo dos híbridos, ao contrário das linhagens SC1155 (1,6), SC1080 (2,5), CMSXS $1102(1,5)$ e CMSXS $1101(2,6)$ que aumentaram o ciclo nos cruzamentos em que participaram.”, está faltando identificação de um dos parentais. Deve ser "Para florescimento os parentais SC $720(-1,6)$, SC 1211(-2,5), RTx2907 (-2,4) e Tx2741 $(-1,1)$ foram os melhores por reduzirem o ciclo dos híbridos, ao contrário das linhagens SC1155 $(1,6)$, SC1080 (2,5), CMSXS $1102(1,5)$ e CMSXS 1101 $(2,6)$ que aumentaram o ciclo nos cruzamentos em que participaram.

O mercado de sorgo granífero exige uma altura de planta entre 1,00 e 1,5 m. Plantas abaixo desta faixa apresentam menor rendimento de grãos, e plantas acima desta faixa tendem a acamar quando a planta seca (Santos et al., 2005; Menezes et al., 2015). As melhores linhagens para cruzamentos em sorgo granífero são aquelas que pouco ou nada contribuem para aumentar a altura nos cruzamentos em que participam. As linhagens CMSXS 230A $(24,5)$ e A $8905(18,2)$ foram as que mais contribuíram para aumentar a altura dos seus híbridos. Ao contrário, as linhagens A 8911(-21,7) e B3 8902A (-16,4) reduziram significativamente a altura dos cruzamentos em que participaram. Estas linhagens devem ser evitadas para produção de híbridos de sorgo granífero. As linhagens que menos influenciaram a altura de seus híbridos foram CMSXS 1006, CMSXS 1011, TX 645A e TX 643A. Das linhagens que contribuíram para aumentar o rendimento de grãos em seus híbridos, somente CMSXS 1006 e CMSXS 1011 não contribuíram para aumentar a altura de planta (Figura 1). As estimativas de CGC para as linhagens restauradoras (Grupo II) são apresentadas na Figura 2. Os parentais SC $720(3,3)$, SC $1211(2,4)$, MR732 $(1,3)$ e Dorado $(0,8)$ apresentaram os maiores valores positivos de CGC para rendimento de grãos, enquanto os parentais Tx $2741(-1,7)$, CMSXS $1102(-1,8)$ e CMSXS $1101(-2,0)$ contribuíram negativamente para rendimento de grãos nos cruzamentos em que participaram. Para florescimento, os parentais SC $720(-1,6)$, SC 1211(-2,5), RTx2907 (-2,4) e Tx2741 $(-1,1)$ foram os melhores por reduzirem o ciclo dos híbridos, ao contrário das linhagens $\operatorname{SC} 1155(1,6)$, SC1080 (2,5), CMSXS (1,5) e CMSXS $1101(2,6)$, que aumentaram o ciclo nos cruzamentos em que participaram. A maioria dos parentais masculinos aumentou ou reduziu significativamente a altura dos cruzamentos em que participou. As linhagens SC 720, SC 1211, MR 732 e Dorado foram as que mais contribuíram para aumentar a altura de seus híbri- 


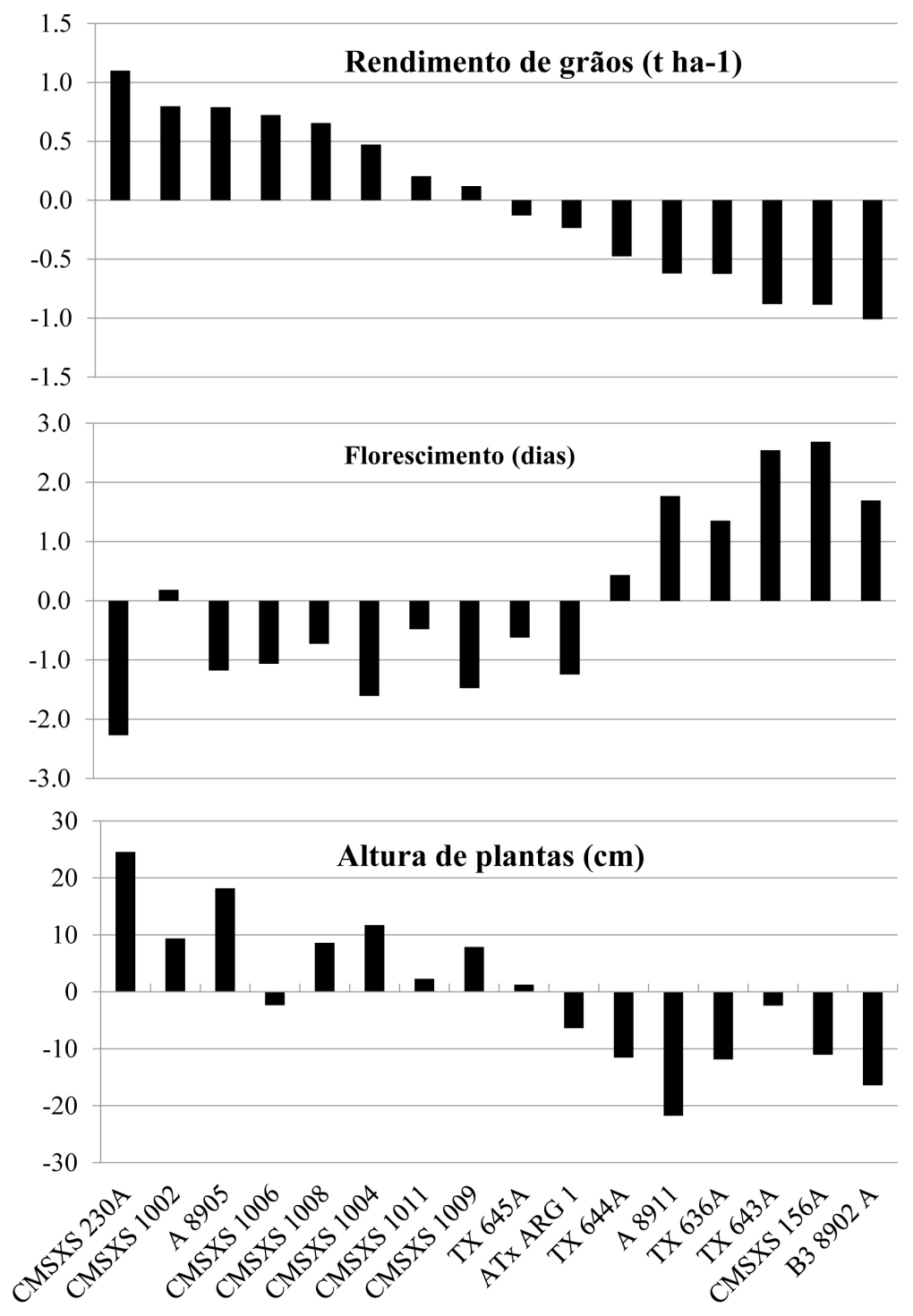

Figura 1. Estimativas dos efeitos da capacidade geral de combinação (CGC) para linhagens macho-estéreis referentes a caracteres rendimento de grãos $\left(\mathrm{t} \mathrm{ha}^{-1}\right)$, florescimento de plantas (dias) e altura de plantas $(\mathrm{cm})$. Sete Lagoas-MG, 2014.

dos, já as linhagens RTx 2907, SC 1080, Tx 2741, CMSXS 1102 e CMSXS 1101 foram as que mais reduziram a altura de plantas dos cruzamentos em que participaram. As linhagens que menos influenciaram a altura de seus híbridos foram SC 1155, Pinolero 1 e RTx436. Observa-se pela figura que as estimativas de CGC para produtividade e altura de plantas foram bem similares. Aquelas linhagens que contribuíram para aumentar a produtividade também o fizeram para altura de plantas. A altura de plantas em sorgo é controlada por quatro genes independentes (Dw1, Dw2, Dw3 e Dw4), em que planta alta domina sobre planta baixa. Plantas com zero de alelos recessivos crescem acima de $4 \mathrm{~m}$ de altura. Em sorgo granífero, 
utilizam-se plantas 3-anão (3-Dw), ou seja, com 3 locos recessivos. No presente trabalho, ocorreu a complementariedade entre linhagens 3-Dw, com genes dominantes em locos diferentes, gerando híbridos 2-Dw. Considerando a característica altura de plantas para a seleção de híbridos, recomenda-se, portanto, utilizar a CEC para auxiliar na seleção, em detrimento da CGC, buscando alguma combinação em que os parentais contribuam menos para a altura de seus híbridos. Caso contrário é necessário a escolha de novas linhagens para futuros cruzamentos.

Os efeitos da CEC, estimados como desvios do comportamento em relação ao que seria esperado com base na $\mathrm{CGC}$, são medidas dos efeitos gênicos não aditivos, tais como efeitos de dominância e epistasia. Normalmente, interessam ao melhorista as combinações híbridas com estimativas de CEC mais favoráveis e que envolvam pelo menos um dos progenitores com elevada CGC para o caráter. Nas Tabelas 2, 3 e 4 são apresentadas as estimativas de CEC para as características de rendimento de grãos, florescimento e altura de plantas, respectivamente. Oitenta e cinco cruzamentos apresentaram CEC positiva para rendimento de grãos (Tabela 2); dentre estes, cinquenta e sete também apresentaram pelo menos um dos genitores com CGC positiva para rendimento. Trinta e sete cruzamentos apresentaram CEC acima de uma tonelada por hectare, sendo que 26 tiveram também pelo menos um parental com CGC positiva. As maiores CEC para rendimento de grãos foram observadas para os cruzamentos CMSXS 1002 x CMSXS 1102, A 8911 x SC 720, ATx ARG 1 x SC1080, CMSXS 1004 x Pinolero 1, B3 8902 A x MR732, CMSXS 1004 x Dorado, CMSXS 1009 x SC1155, TX 645A x SC1080, TX 645A x Pinolero 1 e CMSXS 156A x MR732.
Noventa e seis cruzamentos apresentam CEC para florescimento negativo (Tabela 3 ), entre os quais 73 apresentaram pelo menos um dos parentais com CGC negativa. As maiores estimativas de CEC para dias para florescimento foram obtidas nos cruzamentos CMSXS 1002 x CMSXS 1102, CMSXS 1009 x Pinolero 1, CMSXS 1011 x Pinolero 1, CMSXS 156A x RTx436, CMSXS 1004 x Dorado, TX 643A x SC1080, ATx ARG 1 x SC1080, ATx ARG 1 x SC1211, TX 636A x SC1155 e CMSXS 230A x SC 720.

A seleção para altura de plantas em sorgo granífero deve ser feita com cautela, pois cruzamentos abaixo de $100 \mathrm{~cm}$ e acima de $150 \mathrm{~cm}$ são indesejáveis. Esta característica tem alta correlação com produtividade, e plantas muito altas não suportam panículas grandes, tendendo a acamar. Portanto, para capacidade de combinação, o ideal são aqueles cruzamentos com CEC próxima de zero. Dentro desta ótica, 86 cruzamentos apresentaram CEC entre -5 e +5 , sendo que apenas 21 deles apresentaram pelo menos um dos parentais entre estes limites (Tabela 5). Os cruzamentos que apresentaram menos CEC, negativas e/ ou positivas, foram A 8905 x CMSXS 1102, CMSXS 1008 x MR732, CMSXS 1004 x RTx2907, TX 636A x RTx2907, ATx ARG 1 x Dorado, CMSXS 1011 x RTx2907, CMSXS 1009 x RTx436, CMSXS 156A x SC 720, A 8905 x Dorado e B3 8902 A x SC 720 (Tabela 4).

Como produtividade é uma característica muito influenciada pelo ambiente, novos testes deverão ser feitos com estes híbridos para confirmar os dados encontrados. No entanto, a seleção para altura de plantas pode ser feita com precisão, pois o ambiente influencia menos nesta característica, e aqueles híbridos altos podem ser descartados sem risco de afetar o programa de melhoramento. Na Tabela 5, são apre- 


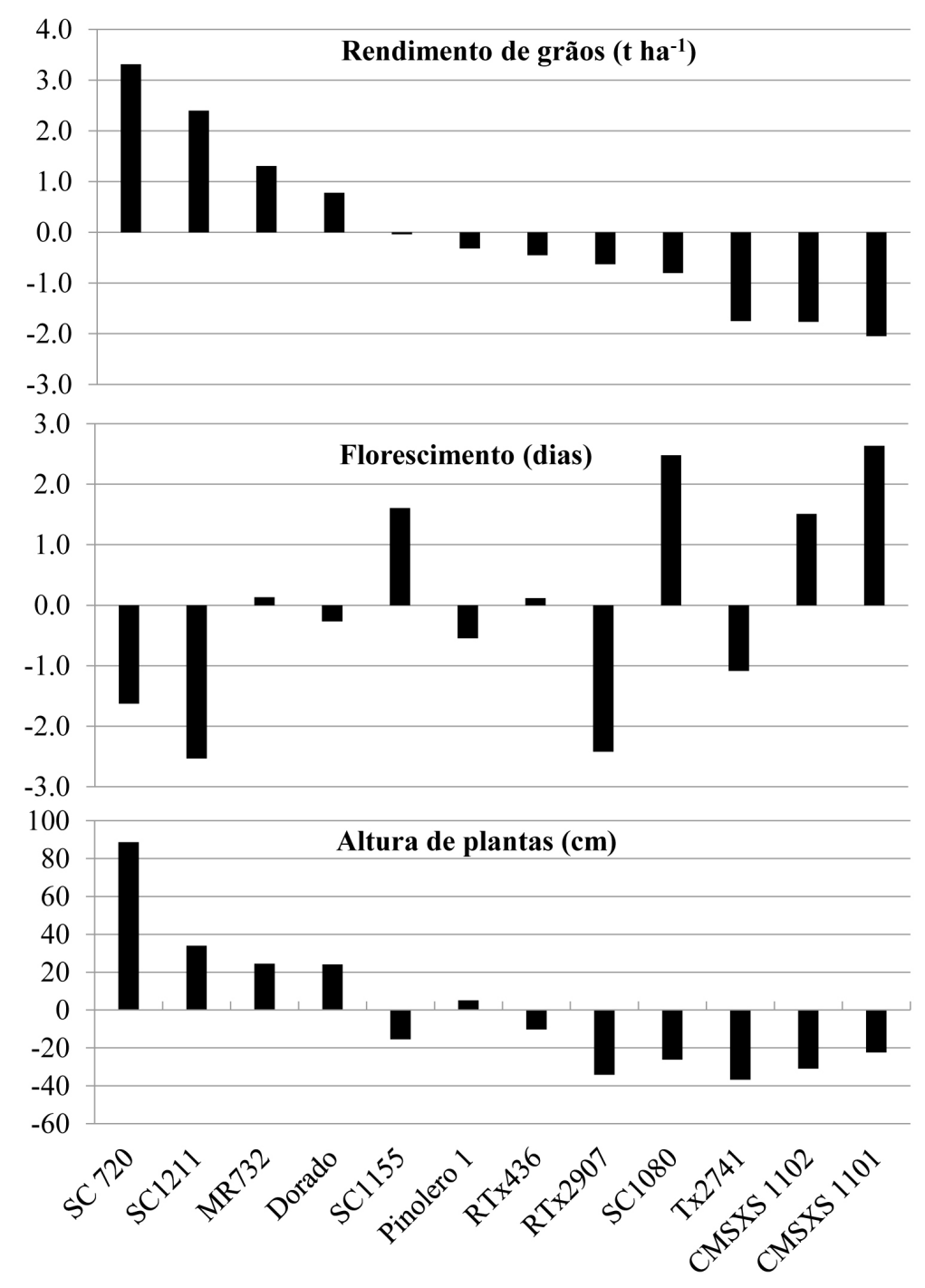

Figura 2. Estimativas dos efeitos da capacidade geral de combinação (CGC) para linhagens restauradoras referentes a caracteres rendimento de grãos $\left(\mathrm{t} \mathrm{ha}^{-1}\right)$, florescimento de plantas (dias) e altura de plantas $(\mathrm{cm})$. Sete Lagoas-MG, 2014.

sentados os 26 híbridos, que, em relação à média das testemunhas, apresentaram rendimento de grãos acima da média, florescimento abaixo da média e altura dentro do padrão exigido para sorgo granífero. Den- tre estes pode-se destacar os híbridos CMSXS 1002 x CMSXS 1102, CMSXS 1006 x RTx2907, ATx ARG 1 x SC1155 e CMSXS 1008 x Tx2741, com rendimentos estatisticamente acima dos demais e elevada CEC. 


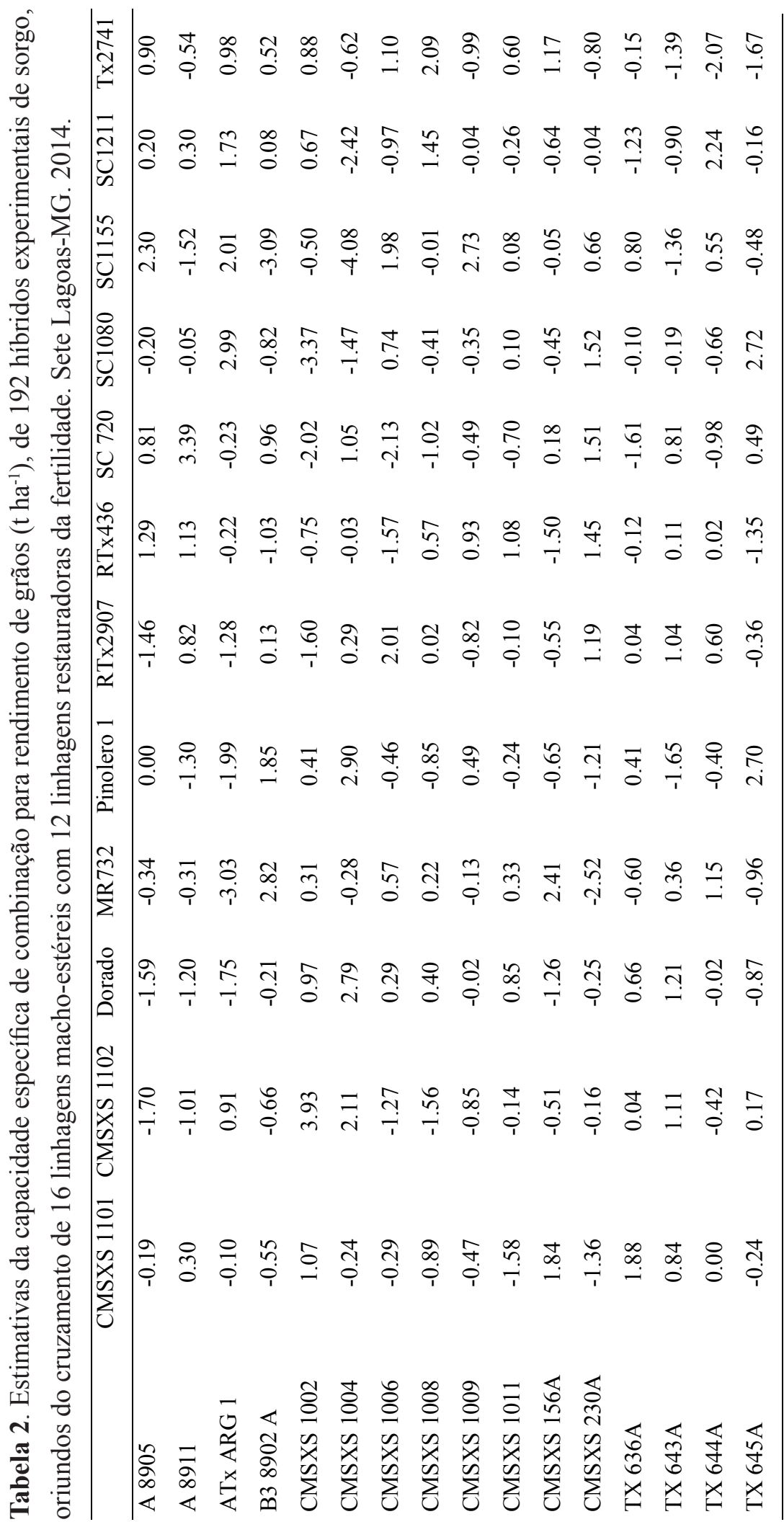




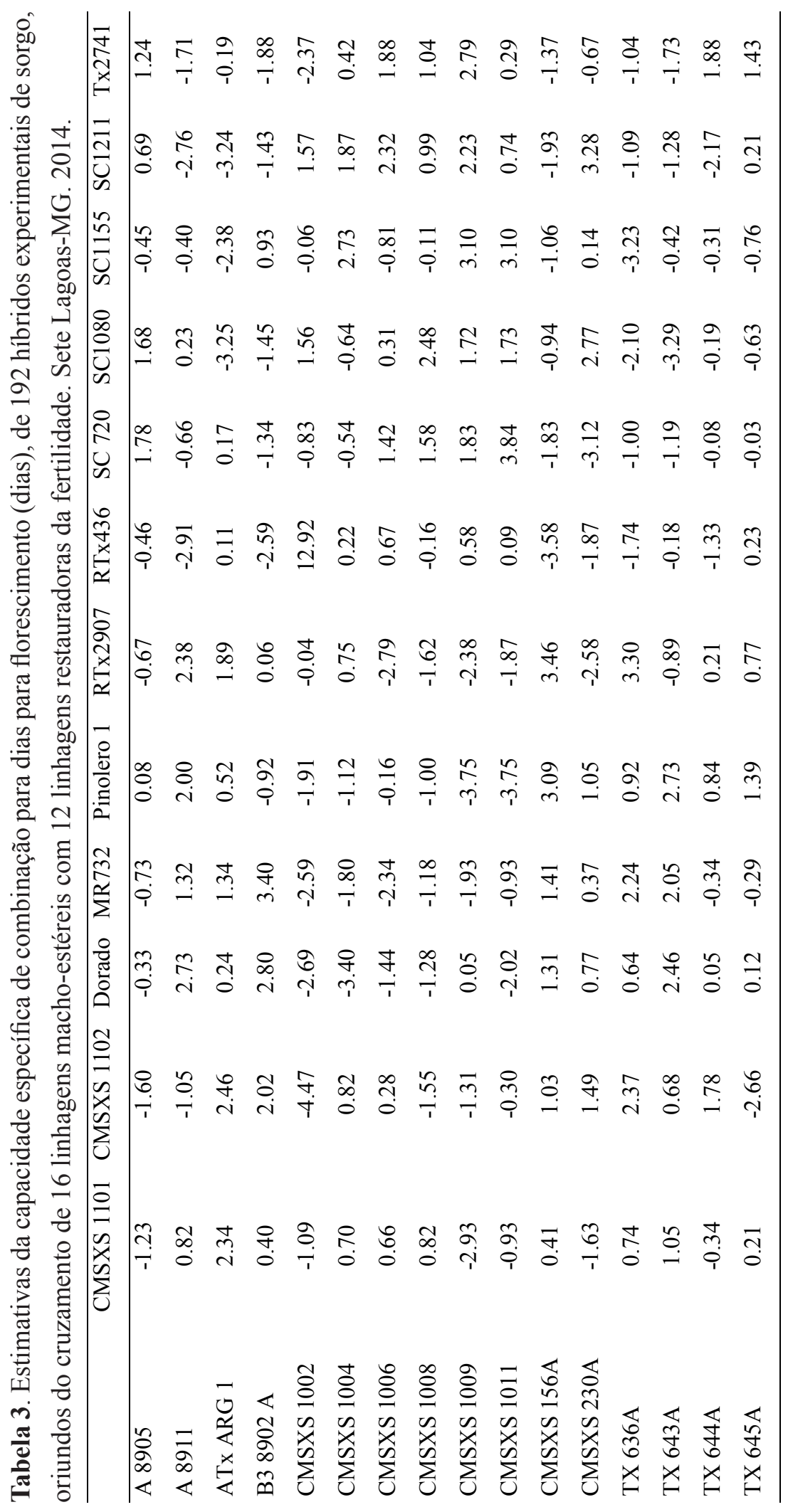




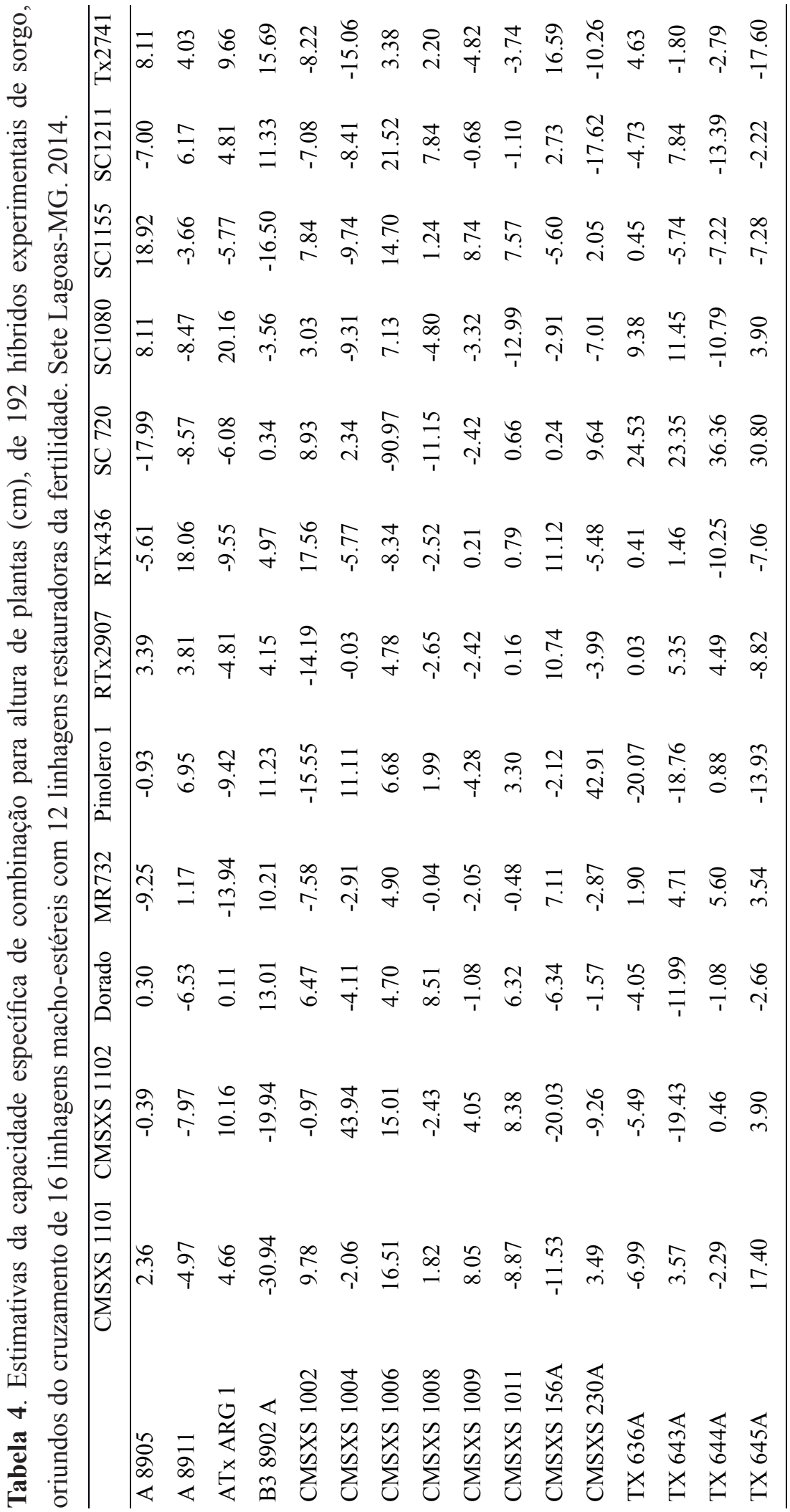




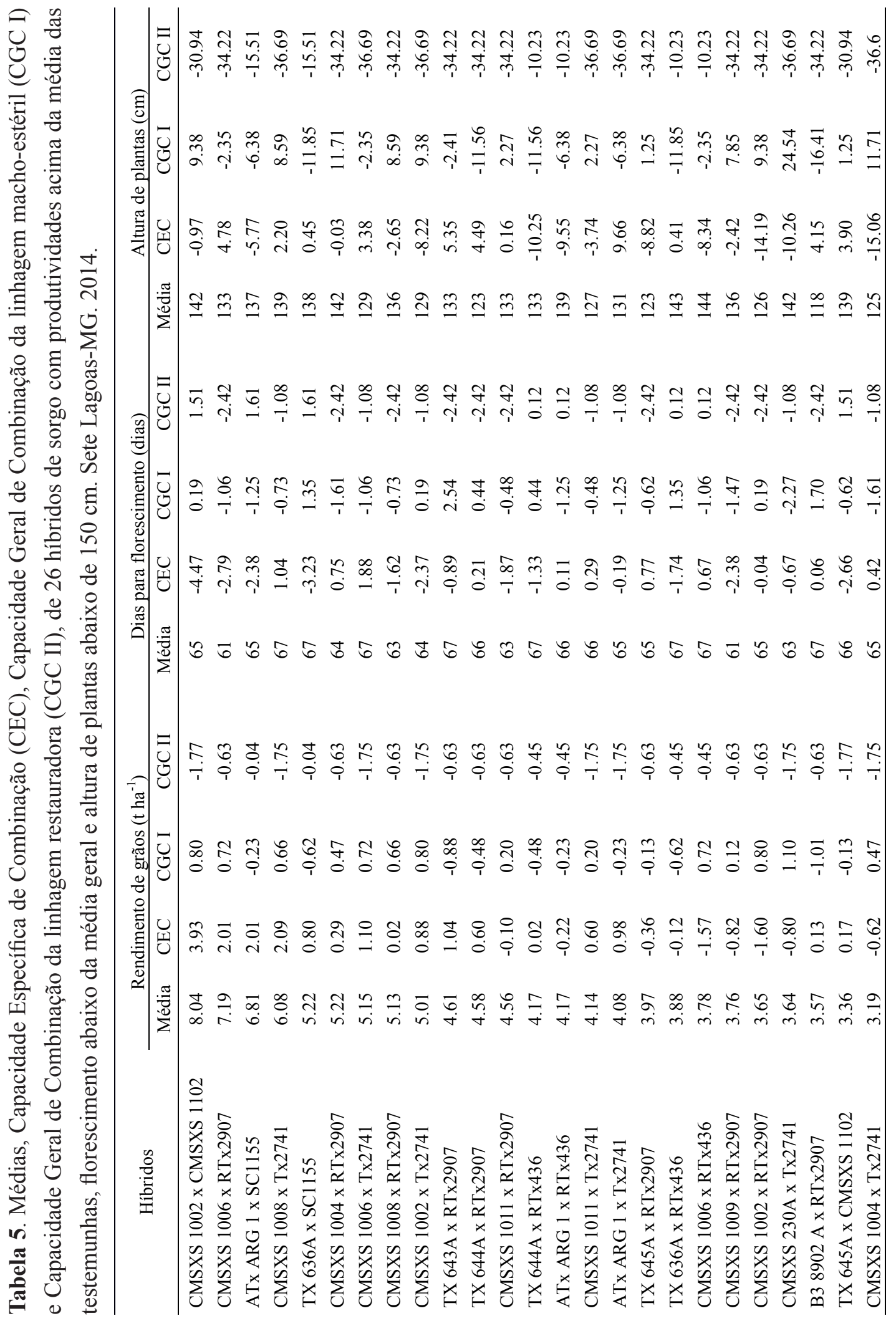




\section{Conclusões}

Houve predominância dos efeitos gênicos aditivos, o que favorece a obtenção de linhagens superiores por meio de seleção de genótipos em populações segregantes provenientes de combinações híbridas promissoras para as características avaliadas.

As linhagens fêmeas CMSXS 1006 e CMSXS 1011 contribuíram para aumentar o rendimento de grãos, sem aumentar os dias para florescimento e altura de plantas.

Todas as linhagens restauradoras que contribuíram para aumentar o rendimento de grãos também o fizeram, com pelo menos $20 \mathrm{~cm}$, para altura de plantas, não devendo serem selecionadas para parentais de sorgo granífero.

Os híbridos CMSXS 1002 x CMSXS 1102, CMSXS 1006 x RTx2907, ATx ARG 1 x SC1155 e CMSXS 1008 x Tx2741 apresentaram rendimentos de grãos acima da média, com florescimento abaixo da média e altura de planta ideal para sorgo granífero.

\section{Agradecimentos}

À Embrapa Milho e Sorgo, Fapemig e ao CNPq, pelo apoio financeiro na realização e divulgação dos resultados.

\section{Referências}

CONAB. Companhia Nacional de Abastecimento. Acompanhamento da safra brasileira: grãos: décimo primeiro levantamento: agosto 2017. Brasília, DF, 2017. 171 p. Disponível em: <http://www.conab.gov. br/conteudos.php? $\mathrm{a}=1253 \& \mathrm{t}=2>$. Acesso em: 4 set. 2017.
CRUZ, C. D. GENES: a software package for analysis in experimental statistics and quantitative genetics. Acta Scientiarum. Agronomy, Maringá, v. 35, n. 3, p. 271-276, 2013. DOI: 10.4025 /actasciagron.v35i3.21251.

CRUZ, C. D.; REGAZZI, A. J.; CARNEIRO, P. C. S. Modelos biométricos aplicados ao melhoramento genético. 4. ed. Viçosa, MG: UFV, 2012. 514 p.

GRIFFING, B. A. Concept of general and specific combining ability in relation to diallel crossing systems. Australian Journal of Biological Sciences, Melbourne, v. 9, n. 4, p. 463-493, 1956.

DOI: $10.1071 / \mathrm{BI} 9560463$.

KENGA, R.; ALABI, S. O.; GUPTA, S. C. Combining ability studies in tropical sorghum (Sorghum bicolor (L.) Moench). Field Crops Research, Amsterdam, v. 88, n. 2/3, p. 251-260, 2004.

MENEZES, C. B.; CARVALHO JÚNIOR, G. A.; SILVA, L. A.; BERNARDINO, K. C.; SOUZA, V. F.; TARDIN, F. D.; SCHAFFERT, R. E. Combining ability of grain sorghum lines selected for aluminum tolerance. Crop Breeding and Applied Biotechnology, Viçosa, MG, v. 14, n. 1, p. 42-48, 2014. DOI: 10.1590/S1984-70332014000100007.

MENEZES, C. B. de; SILVA, A. F. da; TARDIN, F. D. Sorgo safrinha. In: PEREIRA FILHO, I. A.; RODRIGUES, J. A. S. (Ed.). Sorgo: o produtor pergunta, a Embrapa responde. Brasília, DF: Embrapa, 2015. cap. 18, p. 293308. (Coleção 500 perguntas, 500 respostas).

PATERNIANI, E.; CAMPOS, M. S. Melhoramento do milho. In: BORÉM, A. (Ed.). Melhoramento de espécies cultivadas. Viçosa, MG: UFV, 2005. p. 491-552.

RAMALHO, M. A. P.; ABREU, A. F. B.; SANTOS, J. B.; NUNES, J. A. Aplicação da genética quantitativa no melhoramento de plantas autógamas. Lavras: UFLA, 2012. $522 \mathrm{p}$.

ROONEY, W. Sorghum breeding. In: ACQUAAH, G. (Ed.). Principles of plant genetics and breeding. 2nd ed. Chichester: Wiley-Blackwell, 2012. cap. 34, p. 617-627. 
SANTOS, F. G.; CASELA, C. R.; WAQUIL, J. M. 46 f. Dissertação (Mestrado) - Universidade Federal de Melhoramento de sorgo. In: BORÉM, A. (Org.). Viçosa, Viçosa, MG, 2016.

Melhoramento de espécies cultivadas. 2. ed. Viçosa, MG: UFV, 2005. v. 1, p. 429-466.

USDA. United States Department of Agriculture. World

SILVA, K. J. da. Diversidade genética entre linhagens de sorgo granífero utilizando descritores agricultural production. Washington, 2017. Disponível em: $\quad<$ https://www.fas.usda.gov/data/world-agriculturalproduction $>$. Acesso em: 4 set. 2017. 